\title{
ANALISIS KEANDALAN GENERATOR SET SEBAGAI POWER SUPPLY \\ DARURAT APABILA POWER SUPPLY DARI PLN MENDADAK PADAM DI MORODADI POULTRY SHOP BLITAR
}

\author{
BUDI SAPUTRO \\ Fakultas Teknik Universitas Islam Balitar \\ BudiezBudjelz@gmail.com
}

\begin{abstract}
Abstrak
Generator Set terdiri atas Mesin Engine (Motor Penggerak) dan juga Generator / Alternator, seperti yang telah di jelaskan sebelumnya. Mesin Engine yang satu ini menggunakan bahan bakar berupa Solar (Mesin Diesel) atau dapat juga menggunakan Bensin, sedangkan untuk Generatornya sendiri merupakan sebuah gulungan kawat yang di buat dari tembaga yang terdiri atas kumparan statis atau stator dan di lengkapi pula dengan kumparan berputar atau rotor. Dalam proses kerjanya, menurut ilmu fisika, Engine memutar Rotor dalam sebuah Generator yang selanjutnya hal ini menimbulkan adanya Medan Magnet pada bagian kumparan Generator. Selanjutnya Medan Magnet ini kemudian akan melakukan interaksi dengan Rotor yang kemudian akan berputar dan akan menghasilkan sebuah arus listrik dimana hal ini sesuai dengan hukum Lorentz..Pentingnya manfaat dari Mesin Generator Set ini menjadi salah satu alasan mengapa Generator Set atau Genset ini sangat di kenal oleh masyarakat luas, jadi apa bila Anda memiliki usaha yang membutuhkan Mesin Genset ini, jangan sampai mengabaikan Genset ini karena Mesin Generator Set ini dapat memperlancar usaha anda dan menjaga dari situasi yang tidak terduga.
\end{abstract}

Kata kunci: generator, power supply, keandalan.

\section{PENDAHULUAN}

Sebagaimana kita ketahui, pada masa sekarang ini perindustrian di negara kita mengalami perkembangan yang cukup pesat, baik pada perindustrian besar maupun industri kecil. Sebagian besar dari peralatan industri menggunakan generator sebagai power supply cadangan,, Generator menjadi peranan dan fungsi yang sangat penting dalam penyaluran tenaga listrik pada suatu system tenaga listrik.

Mengingat pentingnya generator sebagai power supply darurat dalam mensuplai daya untuk peralatan mekanis, maka peneliti ingin mengetahui dan menganalisa prinsip kerja dari generator serta prosedur perawatan yang benar pada sebuah generator yang disusun dalam laporan skripsi yang berjudul "Analisis Keandalan Generator Set Sebagai Power Supply Darurat Apabila Power Supply Dari PLN Mendadak Padam Di Pabrik Pakan Ternak Morodadi Blitar"

Agar tujuan penulisan tugas akhir ini terfokus pada judul tugas akhir maka peneliti membatasi beberapa permasalahan yang akan dibahas sebagai berikut :

1. Generator yang digunakan berkapasitas $60 \mathrm{Kv}$. Dengan meggunakan diesel sebagai penggeraknya

2. Membahas Bagaimana Prosedur Perawatan Sebuah Generator Sebagai Power Supply Pengganti Saat sumber listrik dari PLN Padam

3. Menjadikan sebuah generator set yang dapat menghasilkan output frekuensi 50 herzt dan tegangan 380 volt.

Adapun tujuan penelitian ini adalah untuk mengetahui prinsip kerja dari generator dan 
bagaimana prosedur pemeliharaan generator yang benar sehingga dapat memperpanjang masa pakai ( life time) dari generator tersebut. Serta untuk mengetahui pengaruh torsi awal sebuah generator untuk menghasilkan suatu nilai tegangan tertentu. Sehingga tegangan yang keluar pada generator generator tetap stabil dan tidak berpengaruh terhadap mesin yang ada. Sekaligus untuk memenuhi tugas akhir karya ilmiah dalam menempuh gelar sarjana strata satu teknik elektro Universitas Islam Balitar.

Manfaat penelitian ini adalah mendapatkan pengertian dan penjelasan bagaimana sebuah generator dapat menjadi power supply pengganti saat daya PLN padam. Dan dapat menghasilkan output tegangan yang tetap stabil

\section{KAJIAN LITERATUR}

\subsection{Definisi Generator Set (Genset)}

Genset (generator set) adalah sebuah perangkat yang berfungsi menghasilkan daya listrik. Disebut sebagai generator set dengan pengertian adalah satu set peralatan gabungan dari dua perangkat berbeda yaitu engine dan generator atau alternator. Engine sebagai perangkat pemutar sedangkan generator atau alternator sebagai perangkat pembangkit. Pada sebuah sistem generator set, penggerak atau engine sangat berpengaruh terhadapan sistem kerja generator tersebut. Karena pada perputaran generator yang stabil dapat menjadikan output generator tersebut menjadi maksimal.

\subsection{Kegunaan Genset}

Kegunaan generator set yang paling utama yaitu menyediakan sumber listrik cadangan ketika sumber listrik dari PLN tiba-tiba padam. Ketika berbicara mengenai Genset, maka hal yang terlintas dalam Pikiran adalah Alat untuk menghidupkan lampu ketika Listrik Padam, meskipun tujuannya tak hanya berfokuskan hanya pada lampu atau penerangan saja, melainkan banyak hal lainnya yang membutuhkan daya listrik, seperti misalnya untuk Pengerjaan Luar Ruangan yang jauh dari sumber daya listrik. Genset sangat dikenal karena kegunaannya sebagai Tenaga Listrik yang bisa diandalkan cukup dengan menggunakan Bahan Bakar Bensin / Solar.

\subsection{Sistem Kerja Genset}

Generator Set terdiri atas Mesin Engine (Motor Penggerak) dan juga Generator I Alternator, seperti yang telah di jelaskan sebelumnya. Mesin Engine yang satu ini menggunakan bahan bakar berupa Solar (Mesin Diesel) atau dapat juga menggunakan Bensin, sedangkan untuk Generatornya sendiri merupakan sebuah gulungan kawat yang di buat dari tembaga yang terdiri atas kumparan statis atau stator dan di lengkapi pula dengan kumparan berputar atau rotor. Dalam proses kerjanya, menurut ilmu fisika, Engine memutar Rotor dalam sebuah Generator yang selanjutnya hal ini menimbulkan adanya Medan Magnet pada bagian kumparan Generator. Selanjutnya Medan Magnet ini kemudian akan melakukan interaksi dengan Rotor yang kemudian akan berputar dan akan menghasilkan sebuah arus listrik dimana hal ini sesuai dengan hukum Lorentz.

\subsection{Konstruksi Generator}

Generator terdiri dari dua bagian yang paling utama, yaitu:

1. Bagian yang diam (stator).

2. Bagian yang bergerak (rotor).

Kontruksi bagian-bagian generator dapat dilihat pada gambar 2.1 berikut. 


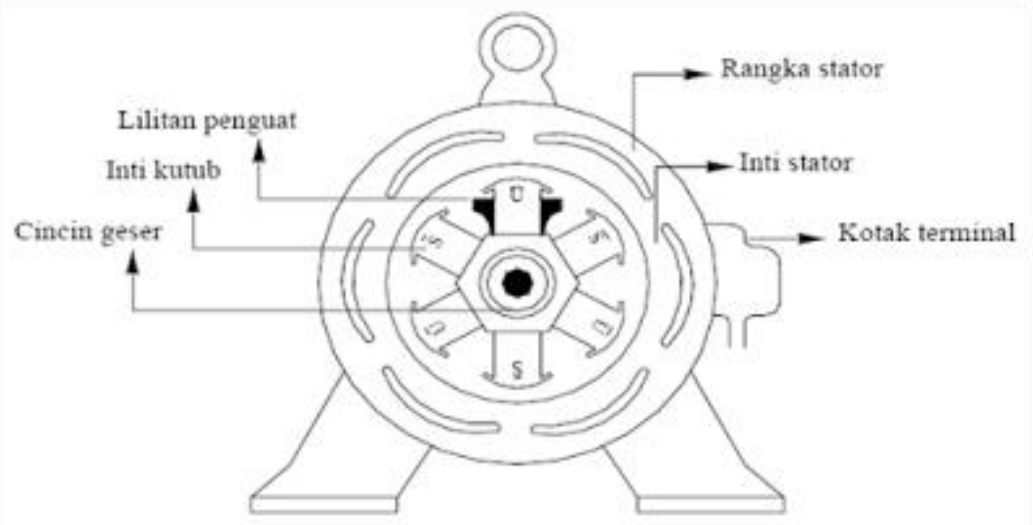

Gambar 2.1 Konstruksi Generator Sinkron [ 3 ]

\subsubsection{Bagian yang diam (Stator)}

Bagian yang diam (stator) terdiri dari beberapa bagian, yaitu:

1. Inti stator.

Bentuk dari inti stator ini berupa cincin laminasi-laminasi yang diikat serapat mungkin untuk menghindari rugi-rugi arus eddy (eddy current losses). Pada inti ini terdapat slot-slot untuk menempatkan konduktor dan untuk mengatur arah medan magnetnya. 2. Belitan stator.

Bagian stator yang terdiri dari beberapa batang konduktor yang terdapat di dalam slotslot dan ujung-ujung kumparan. Masing-masing slot dihubungkan untuk mendapatkan tegangan induksi.

3. Alur stator.

Merupakan bagian stator yang berperan sebagai tempat belitan stator ditempatkan. 4. Rumah stator.

Bagian dari stator yang umumnya terbuat dari besi tuang yang berbentuk silinder. Bagian belakang dari rumah stator ini biasanya memiliki sirip-sirip sebagai alat bantu dalam proses pendinginan.

\subsubsection{Bagian yang bergerak (Rotor)}

Rotor adalah bagian generator yang bergerak atau berputar. Antara rotor dan stator dipisahkan oleh celah udara (air gap). Rotor terdiri dari dua bagian umum, yaitu: 1. Inti kutub

2. Kumparan medan

Pada bagian inti kutub terdapat poros dan inti rotor yang memiliki fungsi sebagai jalan atau jalur fluks magnet yang dibangkitkan oleh kumparan medan. Pada kumparan medan ini juga terdapat dua bagian, yaitu bagian penghantar sebagai jalur untuk arus pemacuan dan bagian yang diisolasi. Isolasi pada bagian ini harus benar-benar baik dalam hal kekuatan mekanisnya, ketahanannya akan suhu yang tinggi dan ketahanannya terhadap gaya sentrifugal yang besar.

Konstruksi rotor untuk generator yang memiliki nilai putaran relatif tinggi biasanya menggunakan konstruksi rotor dengan kutub silindris atau "cylinderica poles" dan jumlah kutubnya relatif sedikit $(2,4,6)$. Konstruksi ini dirancang tahan terhadap gaya-gaya yang lebih besar akibat putaran yang tinggi seperti pada gambar 2.2 berikut. 


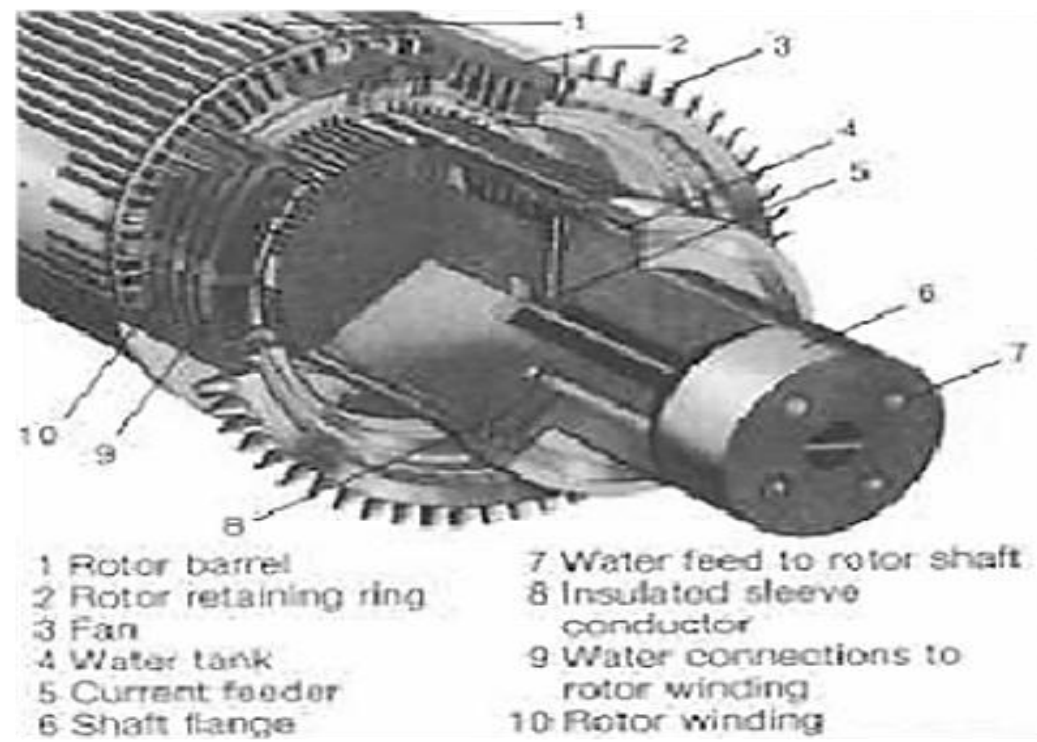

Gambar 2.2 Konstruksi Rotor Kutub Silindris [ 3 ]

Untuk putaran generator yang relatif rendah atau sedang (kurang dari $1000 \mathrm{rpm}$ ), dipakai konstruksi rotor dengan kutub menonjol atau "salient pole" dengan jumlah kutub-kutub yang relatif banyak seperti pada gambar 2.3 berikut.

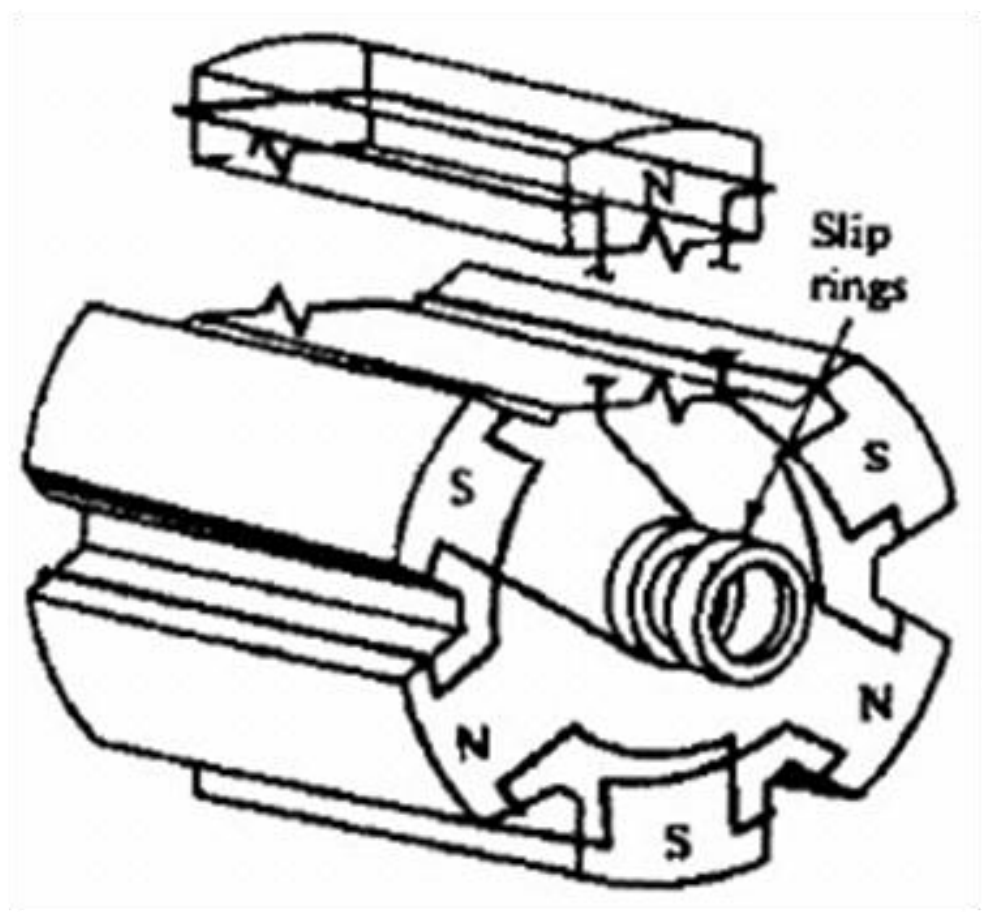

\section{Gambar 2.3 Konstruksi Generator Kutub Menonjol [ 3 ]}

Pada prinsipnya, salah satu dari penghantar atau kutub-kutub ini dibuat sebagai bagian yang tetap sedangkan bagian-bagian yang lainnya dibuat sebagai bagian yang berputar. 


\section{METODE PENELITIAN}

Metode Penelitian dalam penulisan laporan Karya Ilmiah ini adalah metode observasi partisipan, dimana peneliti berperan ganda, yaitu sebagai pengamat sekaligus bagian yang diamati. dalam penelitian ini yang dilakukan penulis adalah mempersiapkan keandalan generator set yang sewaktu-waktu siap dioperasikan sebagai power supply darurat apablia power supply dari PLN padam serta untuk mengetahui nilai output tegangan dari generator itu sendiri. Karena output yang tidak stabil dari sebuah generator akan mengakibatkan kerusakan pada alat-alat mekanik yang ada.

\subsection{Teknik Analisis Data}

Analisis data adalah mengelompokkan, membuat suatu urutan, memanipulasi serta menyingkatkan data, sehingga mudah untuk dibaca. Berdasarkan definisiter sebut analisis data dapat dikatakan sebagai suatu cara untuk mengolah an memaparkan data secara terorganisir dan sistematis.

\subsection{Alat-alat yang digunakan dalam penlitian}

\subsubsection{RPM meter}

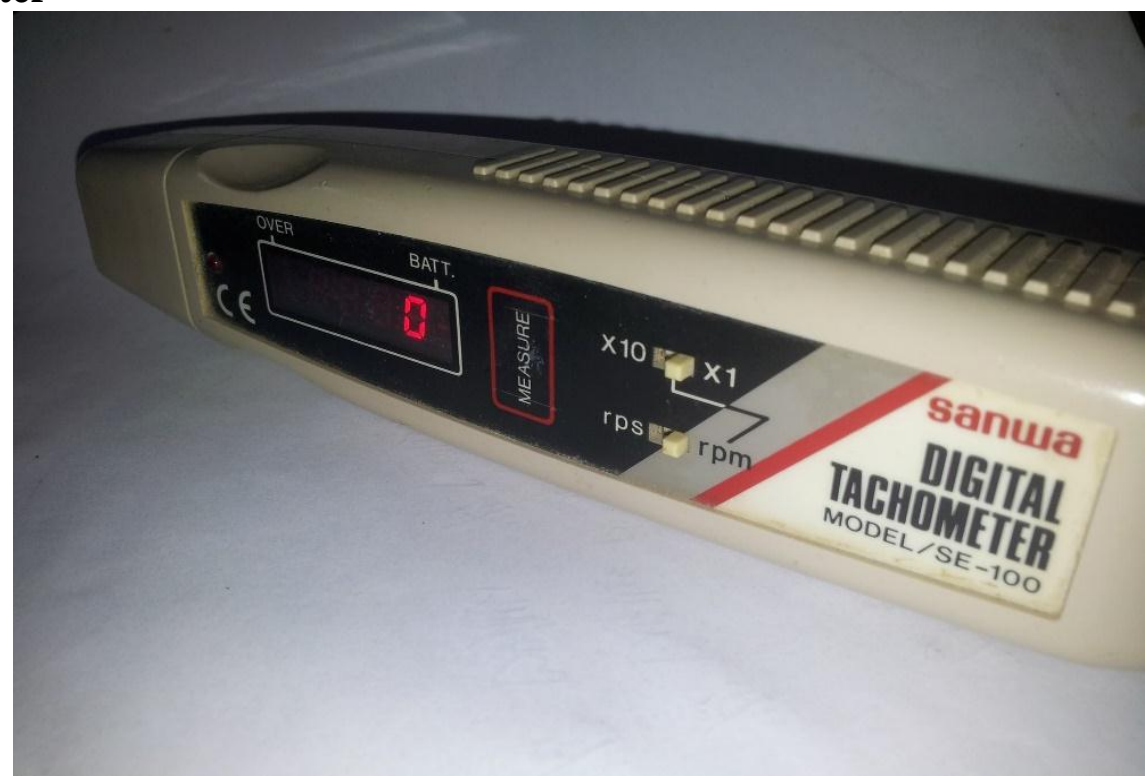

Gambar 3.1 Rpm meter [ 1 ]

Gambar 3.1 adalah RPM meter yaitu sebuah alat untuk mengukur khususnya jumlah putaran yang dilakukan oleh sebuah dalam satu satuan waktu dan sering digunakan pada peralatan kendaraan bermotor. Biasanya memiliki yang menunjukkan kecepatan per menit

\subsubsection{Avo meter}

Fungsi Avometer pada gambar 3.2 adalah alat yang dapat digunakan untuk mengukur arus (ampere), tegangan (volt) dan resistansi (Ohm) dalam satu alat. Selain untuk mengukur ketiga besaran listrik tersebut AVO meter dapat juga dipakai untuk mengukur kondisi komponen elektronika seperti transistor, resistor, trafo. Berdasarkan prinsip kerjanya, ada dua jenis AVO meter, yaitu AVO meter analog (menggunakan jarum putar / moving coil) dan AVO meter digital (menggunakan display digital). Kedua jenis ini tentu saja berbeda satu dengan lainnya, tetapi ada beberapa kesamaan dalam hal operasionalnya. Misal sumber tenaga yang dibutuhkan berupa baterai DC dan probe / kabel penyidik warna merah dan hitam. 


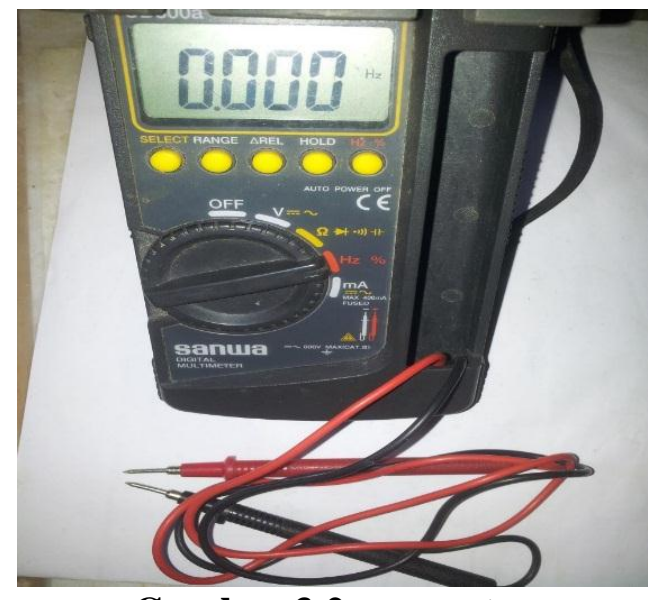

Gambar 3.2 avo meter

\subsection{HASIL PENELITIAN DAN PEMBAHASAN}

\subsubsection{Perhitungan Parameter}

Untuk mendapatkan parameter dari pengukuran dalam penelitian ini memerlukan beberapa alat untuk mendapatkan nilai satuan yang tepat. Serta memerlukan beberapa alat penunjang generator agar generator dapat berfungsi maksimal

\subsubsection{Analisa Data}

Dalam proses analisa ini akan ditentukan berapa torsi atau putaran sebuah generator untuk menghasilkan suatu nilai frekuensi dan berapa tegangan output dari generator. Serta memberikan pembahasan dari hasil pengukuran tentang layak atau tidak nya hasil pengukuran yang diperoleh. Karena nilai output generator sewaktu-waktu dapat berubah. Maka diperlukan pengujian secara berkala terhadap nilai output generator.

Frekuensi Yaitu jumlah kedipan siklus arus bolak-balik (alternating current, AC) per detik. Standar frekuensi yang sering digunakan yakni sebesar 50-60 Hz. Frekuensi listrik ditentukan oleh kecepatan perputaran dari disel sebagai penggerak mula. Salah satu contoh akibat dari frekuensi listrik yang tidak stabil adalah akan mengakibatkan perputaran motor listrik sebagai penggerak mesin-mesin produksi di industri juga tidak stabil, dimana hal ini akan mengganggu proses sistem kerja suatu alat.

Gangguan-gangguan yang terjadi pada sistem frekuensi adalah sebagai berikut:

a. Penyimpangan terus-menerus (Continuous Deviation); frekuensi berada diluar batasnya pada saat yang lama (secara terus-menerus), frekuensi standar $50 \mathrm{~Hz}$ dengan toleransi $0,6 \mathrm{~Hz}$----- $(49,4-50,6 \mathrm{~Hz})$

b. Penyimpangan sementara (Transient Deviation); penurunan atau penaikkan frekuensi secara tiba-tiba dan sesaat.

\subsection{Hasil pengukuran}

Sebuah generator berkapasitas $60 \mathrm{kv}$ memerlukan torsi sebesar $1536 \mathrm{Rpm}$. Dalam nilai torsi 1536 di atas sudah di dapat kan nilai frekuensi yang tepat yakni 50 herzt. Baterai adalah power supply utama untuk mengoperasikan generator. Perlunya daya yang stabil sangat diperlukan dalam start awal generator. Dari gambar di atas dapat dilihat bahwa dua buah baterai berukuran $2 \times 12$ v dengan kapasitas daya 2x100 Ah. Baterai dirangkai secara seri. Dalam perawatan yang baik maka nilai baterai dapat di ukur mendapatkan nilai tegangan $24 \mathrm{v}$. 
Jika dalam sebuah pengukuran nilai baterai menunjukan kurang dari $24 \mathrm{v}$. Maka perlu di charge ulang atau harus perlu diadakan penggantian baterai.

Nilai voltase baterai saat generator beroperasi harus di atas nilai tegangan baterai itu sendiri. Jika nilai voltase baterai $24 \mathrm{v}$, Maka saat generator generator beroprasi nilai baterai harus di atas 24v. Jika nilai baterai tetap berada di nilai 24v maka ada indikasi kerusakan pada dinamo isi. Dinamo isi sangat dibutuhkan untuk pengisian daya kembali saat setelah generator dihidupkan /start. Jika kualitas dinamo isi buruk maka besar kemungkinan daya baterai akan mengalami drop serta tidak akan bisa untuk pengoperasian (start) generator selanjutnya.

Penelitian ini menggunakan diesel mitsubishi 6 silinder dengan kapasitas Rpm mencapai 2200 Rpm. Dengan kapasitas mesin seperti angka yang tercantum diatas maka diesel ini mampu memenuhi torsi yang dibutuhkan generator set berkapasitas daya $60 \mathrm{Kv}$ dengan torsi 1536 . Generator set dalam penelitian ini menggunankan generator Avk yang mempunyai output daya sebesar $60 \mathrm{kv}$. Dalam tulisan pada badan generator tersebut tertulis rotation $1500 \mathrm{Rpm}$. Maka dalam generator tersebut membutuhkan rotasi minimal sebesar $1500 \mathrm{Rpm}$. Dengan diesel yang berkapasitas $2200 \mathrm{Rpm}$ ( pada gambar 4.7 ). Maka dapat disimpulkan torsi yang dibutuhkan dalam generator ini sudah tersuplai baik.

Pada generator 3 phasa, untuk menghasilkan tegangan nominal, tentu di butuhkan kekuatan magnit tetap pada stator nya, pada dasar nya pada stator generator 3 phase, sudah ada magnet permanen, tetapi lemah. ketika stator berputar, pada rotor sudah menghasilkan tegangan kecil yg disebut dengan base voltage, untuk generator 380-400 VAC, base voltage nya sekitar 50 Volt AC. Tegangan 50 volt tadi di hubungkan ke AVR, Output dari AVR mengeluarkan tegangan DC mulai dari 12 s/d 120 VDC, Output dari AVR di hubungan kan ke stator PMG (permanen magnet Generator) berupa generator kecil yg terdapat di depan generator. Rotor PMG menghasilkan tegangan AC, kemudian di searahkan dengan Dioda Rectifier ( terdapat 6 buah -> 3 set). Output dari rotor PMG menghasilkan tegangan DC, kemudian tegangan DC dari rotor PMG di hubungankan ke Rotor Generator, Sehingga di peroleh kekuatan Magnet yg lebih besar. dengan semakin besar nya kekuatan magnet, maka akan semakin besar pula tegangan output yang keluar dari generator. Fungsi AVR mengontrol agar tegangan generator tidak melebihi dari tegangan nominal.

Power Factor (Faktor Daya) yang juga selalu ditulis sebagai cos $\varnothing$, merupakan bagian yang cukup penting dalam pengoperasian suatu Generator Listrik. Karena menurunnya faktor daya $(\cos \varnothing)$ akan berakibat turunnya efisiensi pembangkit dalam menampung beban kerja serta akan memperbesar kemungkinan terjadinya kerusakan pada sistem pembangkit atau sistem beban listrik, sehingga perlu adanya usaha untuk memperbaiki faktor daya tersebut.

Untuk kepentingan perbaikan faktor kerja ini, diperlukan pemasangan beberapa unit kapasitor yang dihubungkan secara parallel seperti yang terlihat pada gambar 4.10. sistem pembangkit listrik yang kita kenal sebagai Capacitor Bank dan dilengkapi dengan Power Factor Automatic Regulator (pengatur otomatis kerja Capacitor) dan berfungsi memperbaiki faktor daya pembangkit melalui pengoperasian secara automatis unit-unit kapasitor berdasarkan besar/kecilnya beban kerja pembangkit (daya reaktif).

Hasil pengukuran di atas dapat menujukan bahwa sebuah generator dengan daya $60 \mathrm{kv}$. Memerlukan torsi ( putaran ) sebesar $1536 \mathrm{Rpm}$ untuk mampu menghasilkan frekuensi sebesar $50 \mathrm{~Hz}$. Serta untuk mendapatkan tegangan di angka $380 \mathrm{v}$. Kita menggunakan AVR (automatic voltage regulator ) sebagai pengatur tegangan output nya

\section{KESIMPULAN}

Berdasarkan analisis yang telah dilakukan di morodadi poultry shop, peneliti menarik beberapa kesimpulan antara lain sebagai berikut: 
1. Berdasarkan hasil analisa sebuah generator frekuensi sangat berpengaruh besar terhadap suatu nilai tegangan yang keluar dari output generator tersebut

2. Dengan adanya pengukuran terhadap torsi sebuah generator kita mampu menentukan frekuensi terhadap output tegangan generator, sehingga frekuensi yang stabil mampu menjadikan kerja sebuah alat menjadi maksimal

3. Dengan alat ukur Rpm meter,avo meter dan herzt meter dapat memudahkan pengukuran secara rutin dan berkala

4. Pengecekan dan pengukuran secara berkala menjadikan generator menjadi handal dan dapat di operarsikan sewaktu-waktu daya listrik dari PLN padam

5. Dengan megetahui pengaruh torsi terhadap nilai frekuensi kita dapat mempertahankan usia pakai (life time) alat-alat mekanis yang memakai tegangan dari output generator

6. Serta Melakukan perbaikan (maintenace) secara rutin supaya kerusakankerusakan kecil dapat segera di atasi sehingga tidak menimbulkan kerusakan yang terlalu signifikan

Adapun saran dari peneliti antara lain sebagai berikut:

1. Sebaiknya perusahaan membuat SOP (Standart Operational Procedure) pengoperasian khusunya untuk sebuah generator, Sehingga tidak menggangu sistem kerja alat-alat mekanis serta memperpanjang usia pakai (life time) alat-alat mekanis

2. Membuat Scheduling Maintenance System yang meliputi

a. Perawatan alat-alat mekanis

b. Saat penggantian / pelumasanbearing generator

c. Perawatanberkala pada baterei / Accu

d. Serta pengecekan terhadap saluran transmisi yang ada

3. Pelunya adanya otamatisasi pada generator set agar waktu yang dibutuhkan dengan rangakain kontrol lebih cepat dari pada mengandalkan tenanga manual. Sehingga generator set dapat lebih cepat beroperasi

4. Untuk Prodi teknik Elektro Universitas Islam Balitar agar menambah peralatan praktikum untuk mahasiswa, sehingga proses belajarmahasiswa, terkait dengan pembuktian teoritis semakin mudah dilaksanakan.

5. Membuat standart penulisan skripsi atau karya ilmiah yang dipatenkan, sehingga akan memudahkan mahasiswa dalam menyusun karya ilmiah untuk tahun tahun berikutnya.

\section{DAFTAR PUSTAKA}

Dokumentasi morodadi PS Srengat Kab.Blitar

Anonymous,(2009)generator,retrived 03.08.2016/19.21,from blog http://lhupuz.blogspot.co.id/2009/11/bab-i-pendahuluan-1.html,

Anonymous,(02.2016) pengertian-bagian-bagian-generator,retrived 12.08.2016/20.43, from blog

http://blog-definisi.blogspot.co.id/2016/02/pengertian-bagian-bagian-generator.html,

Anonymous,(10.2009)pengertian-dan-komponen-capasitor-bank,retrived 13.08.2016/21.55,from blog http://fzlhitech1978.blogspot.co.id/2012/10/pengertian-dan-komponen-capasitor-bank.html, 
Anonymous,(10.2015)baterai-accu-fungsi-tipe-dan-konstruksi,retrived 21.08.2016/19.53,from blog

http://teknologi-otomotif-update.blogspot.co.id/2015/10/baterai-accu-fungsi-tipe-dankonstruksi_27.html,

Anonymous,(02.2011) generator-ac-dan-dc retrived 26.08.2016/21.48,from blog http://bullhuck-pendidikan.blogspot.co.id/2011/02/generator-ac-dan-dc.html,

Anonymous,( 2011) sejarah-generator-diesel retrived 13.09.2016/19.22,from blog http://sylva23.abatasa.co.id/post/detail/34092/sejarah-generator-diesel

Anonymous,(10.2015) sejarah- teori-induksi-elektromagnetik retrived 13.09.2016/20.11,from wibesite

http://www.prosesbelajar.com/2015/10/teori-induksi-elektromagnetik-kelas-xii-ipa.html

Anonymous,(07.2013) sistem-eksitasi-generator retrived 13.09.2016/20.38,from blog http://puballattack.blogspot.co.id/2013/07/sistem-eksitasi-generator.html

Anonymous,(12.2008) proteksi-generator retrived 13.09.2016/19.22,from blog http://dunia-listrik.blogspot.co.id/2008/12/proteksi-generator.html 